\title{
The Possibility of Self-Determined Death Eliminates Mortality Salience Effects on Cultural Worldview Defense: Cross-Cultural Replications
}

\author{
Hongfei Du1, Immo Fritsche ${ }^{2}$, Zenobia Talati ${ }^{3,4}$, Emanuele Castano ${ }^{5}$, Eva Jonas ${ }^{6 *}$ \\ ${ }^{1}$ Department of Psychology, University of Macau, Macau, China \\ ${ }^{2}$ Institut für Psychologie, Universität Leipzig, Leipzig, Germany \\ ${ }^{3}$ School of Psychology, University of Western Australia, Crawley, Australia \\ ${ }^{4}$ Faculty of Health Sciences, School of Psychology and Speech Pathology, Curtin University, \\ Bentley, Australia \\ ${ }^{5}$ Department of Psychology, New School for Social Research, New York, USA \\ ${ }^{6}$ Department of Psychology, University of Salzburg, Salzburg, Austria \\ Email:dhfpsy@gmail.com, Immo.Fritsche@uni-leipzig.de,Zenobia.Talati@curtin.edu.au, \\ castanoe@newschool.edu, "eva.jonas@sbg.ac.at
}

Received 5 May 2016; accepted 28 June 2016; published 1 July 2016

Copyright (C) 2016 by authors and Scientific Research Publishing Inc.

This work is licensed under the Creative Commons Attribution International License (CC BY).

http://creativecommons.org/licenses/by/4.0/

(c) (i) Open Access

\begin{abstract}
Contemplating the inevitability of one's own death can deeply affect a person's subjective sense of control, eliciting symbolic responses to restore control through cultural worldview defense. Research supporting this perspective has shown that reminders of one's own death (i.e., uncontrollable death) can increase worldview defense, whereas self-determined dying (i.e., controllable death) does not (Fritsche, Jonas, \& Fankhänel, 2008). To date, all supportive evidence comes from the German culture and it remains unclear whether this effect can be replicated in non-German cultures. We conducted two studies to investigate the cross-cultural validity of this effect and replicated the effect in both a highly individualistic culture (i.e., the United States) and a highly collectivistic culture (i.e., China). The increased ingroup identification observed after reminders of uncontrollable death supports the model of group-based control.
\end{abstract}

\section{Keywords}

Lack of Control, Self-Determined Death, Mortality Salience, Group-Based Control

\footnotetext{
${ }^{*}$ Corresponding author.
}

How to cite this paper: Du, H. F., Fritsche, I., Talati, Z., Castano, E., \& Jonas, E. (2016). The Possibility of Self-Determined Death Eliminates Mortality Salience Effects on Cultural Worldview Defense: Cross-Cultural Replications. Psychology, 7, 1004-1014. http://dx.doi.org/10.4236/psych.2016.77101 


\section{Introduction}

A sense of control is important to people all over the world. When people feel that their personal control is threatened, they are strongly motivated to restore their perception of control through different means. For example, research has shown that people tend to re-establish the perception of control by supporting external systems (e.g., God or the government) that have power to control the world (Kay et al., 2008) or by clinging more closely to important ingroups (e.g., neighborhood groups, people of the same ethnicity) that are incorporated into their social self (Fritsche, Jonas, \& Kessler, 2011, 2013). According to the group-based control restoration model (Fritsche et al., 2011, 2013), thinking and acting as a group member, defending one's group-related cultural beliefs and behaving according to cultural norms can help to restore one's sense of control.

Group-based control restoration might also function as a buffer against existential terror. Terror management theory (TMT) proposes that people use their cultural worldview (a system of beliefs and values based on their various group memberships) to cope with the terror of human mortality (e.g., Greenberg, Solomon, \& Pyszczynski, 1997). Hundreds of experiments have shown that when participants think about their own death, they defend their cultural worldview more strongly than controls who think about other (aversive) events (Arndt \& Greenberg, 1999; Burke, Martens, \& Faucher, 2010). It is proposed that worldview defense buffers death anxiety as it allows individuals to create meaning in an otherwise random life and feel as though they will continue to exist symbolically through their cultural ingroups after their physical death (Castano \& Dechesne, 2005). However, researchers have observed that mortality salience not only leads to cultural worldview defense, but also results in feelings of helplessness (Kazén, Baumann, \& Kuhl, 2005), a lack of perceived control (Martin, 1999) and increased implicit motivation to regain control (Fritsche et al., 2008; Study 5). Therefore, it is plausible that mortality salience reduces people's perceptions of control (since death is often uncontrollable), which in turn, leads to worldview defense as a group-based control restoration strategy (Fritsche, Jonas, \& Kessler, 2011, 2013).

As noted earlier, Fritsche and colleagues (Fritsche et al., 2008, 2013; Fritsche, Jonas, \& Kessler, 2011) proposed that people strive to uphold a sense of control through the self. However, in situations where personal control seems thwarted, people will demonstrate collective control through situationally important social identities. Support for the model comes from studies showing that making salient personal lack of control increases the attractiveness of agentic ingroups (Stollberg, Fritsche, \& Bäcker, 2015a), conformity to salient ingroup vs. outgroup norms (Stollberg, Fritsche, \& Jonas, 2015b), as well as ingroup bias (Greenaway et al., 2014) and progroup action intentions, particularly in people who were highly identified with their ingroup or who perceived that collective agency might be at stake (Fritsche et al., 2013).

Since the very fact of inescapable mortality may pose one of the most distinct and extended threats to personal control (Martin, 1999), the effects of mortality salience on the support and defense of cultural ingroups might be at least partially explained in terms of group-based control restoration.

Fritsche et al. (2008) sought to disentangle the effects of low personal control and mortality salience on worldview defense by manipulating the degree of control associated with death. In one study using a German sample, one third of their participants imagined that they suffered from an incurable disease which caused them to die (uncontrollable death condition) whereas another third imagined that they suffered from an incurable disease which would lead to a long, painful death and thus they had chosen to end their life (self-determined death condition). The final third completed parallel questions about dental pain (as a control condition). Death-related thoughts were more accessible in both the uncontrollable death and the self-determined death conditions compared to the dental pain group. However, only participants who wrote about an uncontrollable death showed increased worldview defense compared to those who thought of a self-determined death or dental pain.

In another study, Fritsche et al. (2008) extended this paradigm by comparing mortality salience with and without control to relationship uncertainty with and without control. Only the situations without control resulted in stronger cultural worldview defense (with no independent effect of mortality salience), suggesting that ingroup defense was used as a mechanism for regaining control. Adopting the described manipulation in a further study (Fritsche et al., 2013, Study 4) revealed that the derogation of an outgroup following uncontrollable (vs. self-determined and no) death was most pronounced when ingroup homogeneity was threatened.

Acting as a group member, in terms of the collective "we" instead of the personal "I" (Castano, Yzerbyt, Paladino, \& Sacchi, 2002), may restore a sense of control through the (social) self when personal control is threatened (Fritsche et al., 2008, 2011, 2013). The aim of this manuscript is to further explore this notion by showing 
that death reminders increase ingroup bias and ingroup support when they indicate uncontrollability but not when partial control over death is made salient. Specifically, we aimed to replicate the previous findings of (Fritsche et al., 2008) across diverse cultural contexts.

\section{The Influence of Cultural Context}

Reminders of (uncontrollable) death have been shown to increase cultural worldview defense across different cultures (e.g., Du et al., 2013; Greenberg et al., 1990). However, the strength of this effect varies by region. Burke et al. (2010) found that mortality salience manipulations had a significantly greater effect on Americans than Europeans and a reduced effect in Asian cultures. Furthermore, Asian cultures appear to de-emphasize the importance of personal control (Sastry \& Ross, 1998) and believe more strongly in external sources of control (Markus, Uchida, Omoregie, Townsend, \& Kitayama, 2006; Smith, Trompenaars, \& Dugan, 1995) and control based in the social context (conjoint control; Iyengar \& Lepper, 1999; Morling \& Kitayama, 2007). These findings do not negate the fact that these individuals may require a certain basic level of control and can feel threatened when it is taken away. The view that control striving and restoration of control are universal processes, finds support in a meta-analysis by Cheng, Cheung, Chio, and Chan (2013), showing that the negative effect of personal control beliefs on depressive symptoms can be generalized over individualistic and collectivistic cultures.

To investigate whether the effects of uncontrollable vs. self-determined death would be replicated in nonGerman cultures, a highly individualistic (i.e., the United States) and a highly collectivistic (i.e., China) culture were studied. This strategy was guided by the Hofstede's index of individualism (Hofstede, 1991), in which the individualism scores of the United States, Germany and China are 91, 67 and 20, respectively (higher score indicating a more individualistic culture). Replicating these findings would strengthen the control explanation of mortality salience effects on cultural worldview defense and would support the notion that threats to people's sense of general control universally result in defense of ingroups and their worldviews. In addition, successful replications in varied cultures would enhance confidence that the effects of self-determined death were not due to biased samples or random/systematic error (Henrich, Heine, \& Norenzayan, 2010; Open Science Collaboration, 2015).

\section{The Present Research}

Previous findings in German/Austrian samples suggest that the lack of control experienced during mortality salience may, at least in part, be driving the cultural worldview defense response (Agroskin \& Jonas, 2013; Fritsche et al., 2008, 2013). In the present paper, we investigated if these results can be obtained in American and Chinese cultures. Moreover, we extended previous research in two ways: a) we further explored the role of ingroup identification on the effects of uncontrollable vs. self-determined death (Study 1), and b) tested whether the effects of self-determined death extend to other measures of cultural worldview defense (i.e., evaluations of moral transgressions, Study 2).

\subsection{Study 1}

Study 1 was a conceptual replication of earlier studies showing the effect of uncontrollable death on ingroup bias in German samples (Fritsche et al., 2008), in a highly individualistic culture, the United States. In this study, the main dependent variable was the evaluations of an ingroup (New Yorkers) and an outgroup (people from suburban and rural areas). Identification with New York was also measured as a potential moderator of the effect of mortality salience on ingroup defense.

\subsubsection{Method}

\section{1) Participants}

Forty-four New York City residents (22 females) with an average age of 23.66 years (SD $=4.71)$ replied to online advertisements and volunteered to take part in the study at a university campus in New York City. Ten further participants who indicated not being a current New York resident were not included in the study as the dependent variable addressed New Yorkers as an ingroup. The recruiting strategy was to recruit as many participants as it was possible within 8 business days ${ }^{1}$. All participants received an incentive of \$6 US.

\footnotetext{
${ }^{1}$ Data collection was bounded due the fixed end date of the first author's research stay.
} 
2) Procedure

The study, ostensibly on the relationship between self-relevant information and social judgments, was administered through MediaLab (Jarvis, 2004a) and DirectRT (Jarvis, 2004b). Participants were seated in a singlesession laboratory in front of a computer. After reading the instructions participants answered socio-demographic questions and a locus of control measure (Mirowsky \& Ross, 1991)2. Then, they randomly received one of the three different instructions: uncontrollable death, self-determined death, or dental pain (Fritsche et al., 2008). In the uncontrollable death condition, participants answered the following questions: 1) Imagine you suffer from an incurable infectious disease. One month after receiving this diagnosis you die. Please briefly describe the emotions that the thought of your own death arouses in you; and 2) Jot down, as specifically as you can, what you think will happen to you as you die by the disease and once you are physically dead. In the self-determined death condition participants answered the following questions: 1) Imagine you suffer from an incurable, infectious disease. This disease rapidly leads to a crippling of the whole body, followed by a long, drawn-out, and painful death due to lung collapse. One month after receiving this diagnosis you choose to end your own life in your own way and die a self-determined death. Please briefly describe the emotions that the thought of your own death arouses in you. and 2) Jot down, as specifically as you can, what you think will happen to you as you die a self-determined death and once you are physically dead. In the control condition, participants answered parallel questions about dental pain, which is frequently used as a control task in mortality salience research (Greenberg, Simon, Pyszczynski, Solomon, \& Chatel, 1992a). This was followed by the 20-item PANAS $^{3}$ (Watson, Clark, \& Tellegen, 1988), and a self-esteem IAT ${ }^{4}$ serving as a delay.

The dependent measure of group evaluations was preceded by a warm-up task in which participants rated different professional groups (office administrators, hairdressers, police officers, nurses) on four traits (well-organized, anxious, uncompromising, open). The purpose of this warm-up task was to increase people's readiness to form global evaluations of groups of people. For the actual group evaluations measure, participants were asked to indicate to what extent each of 24 attributes described New York inhabitants (the ingroup) on 10-point scales from 1 (not at all) to 10 (very much). The attributes were collected on an ad-hoc basis for representing likely (self-) stereotypes about New Yorkers and inhabitants of rural areas. Participants then rated this set of attributes with regard to how much they described inhabitants of suburban or rural places (the outgroup). The order of presentation of ingroup and outgroup judgments was counterbalanced.

The attributes represented qualitatively different dimensions of judgment for the ingroup and the outgroup. A factor analysis on judgments about New York inhabitants suggested a six factor solution (KMO = .51; scree-plot criterion; 66.76\% explained variance) with only the first factor representing an unambiguously positive stereotype of New Yorkers as warm and creative (6 items: helpful, reliable, pleasant, warm, creative, friendly; $\alpha=.83$; $22.55 \%$ explained variance). The second factor described a negative stereotype of being aggressive and superficial (5 items: patient [reversed], patriotic [reversed], superficial, aggressive, rigid; $\alpha=.72 ; 13.64 \%$ explained variance) whereas the other factors were of mixed evaluative content $t^{5}$. Together, the first two factors explained $36.19 \%$ of the variance.

Factor analysis on suburban attributes revealed five factors (KMO $=.53$; scree-plot criterion; $58.08 \%$ explained variance) with friendly and patriotic (5 items: helpful, reliable, patient, patriotic, friendly; $\alpha=.78$; $19.77 \%$ explained variance) as indicating a clearly positive evaluation and prejudiced and noncreative ( 3 items: open-minded [reversed], creative [reversed], prejudiced; $\alpha=.67 ; 14.52 \%$ explained variance) as representing a negative evaluation ${ }^{6}$. Together, $34.29 \%$ of variance was explained by these first two factors of positive and negative judgment. As we were interested in clearly positive and negative judgments of New Yorkers and rural people, we focused only on the first two factors describing each of the groups in clearly positive or negative

\footnotetext{
${ }^{2}$ Locus of control did not significantly moderate the reported effects. Given the low number of participants we were able to recruit and the fact that the uncontrollable death effect was only present for high identifiers, we do not include any 3-way moderator analyses for the locus of control measure due to power concerns.

${ }^{3}$ Positive and negative affect were not affected by the manipulation (all $p \mathrm{~s}>.24$ ).

${ }^{4}$ Implicit self-esteem did not moderate the reported effects. As for the locus of control measure, we do not include advanced moderator analyses due to power concerns.

${ }^{5}$ The third factor described New Yorkers as sad (2 items: uncertain, sad, $r=.62$ ), the fourth factor was about being conceited and poor (4 items: naive, conceited, poor, prejudiced; $\alpha=.62)$, the fifth factor was constituted of the traits "just" and "brazen" ( $r=.33)$, and the sixth factor only represented the item "old-fashioned".

${ }^{6}$ Factors 3 to 5 were "intellectual and brazen" (2 items; $r=.26$ ), "inappropriate" (3 items: boring, uncertain, old-fashioned; $\alpha=.55$ ), and "poor and rigid" ( 3 items: poor, sad, rigid; $\alpha=.43$ ).
} 
terms and that alone explained a higher amount of variance than the remaining factors together.

As a measure of ingroup identification we used responses to one item ("I identify with the place I actually live at”) rated on a 10-point scale from 1 (not at all) to 10 (very much). A second item, measuring ingroup disidentification ("Living at the place I actually live has nothing to do with my identity"), was not significantly correlated with the identification item and was thus not included as a measure of identification. Finally, participants answered a brief post-experimental questionnaire, were fully debriefed, thanked, and released.

\subsubsection{Results}

We tested whether uncontrollable death salience (vs. self-determined death and dental pain salience; critical contrast: $+2-1-1$ ) would lead highly identified New Yorkers to evaluate their ingroup more positively. Thus, we submitted participants' scores on the first factor describing New Yorkers as warm and creative to a multiple regression analysis with interaction tests (Aiken \& West, 1991), simultaneously entering as predictors the critical contrast (+2 -1 -1), the orthogonal contrast $\left(\begin{array}{lll}0 & 1 & -1\end{array}\right)$, and ingroup identification (centered) as well as the interaction of each contrast and ingroup identification ${ }^{7}$. No main effects emerged (all $p s>$.13), but, as predicted, we found a significant interaction effect of the critical contrast $(+2-1-1)$ and ingroup identification , $b=.13$; $t(38)=2.43 ; p=.02 ; \beta=.36$. Simple slope analyses show that uncontrollable death salience (compared to self-determined death and dental pain salience) increased ratings for those participants who were highly identified with their city ( $+1 \mathrm{SD}), b=.50 ; t(38)=2.35 ; p=.02 ; \beta=.51$, but not for those who were less identified $(-1$ $\mathrm{SD}), b=-.18 ; t(38)=-0.93 ; p=.36 ; \beta=-.18$. For illustration, the interaction effect is depicted in Figure 1 , using a median split on identification scores. No effects involving the critical or the orthogonal contrast were observed for the negative ingroup judgment factor or for the positive and negative evaluation of the suburban outgroup (all ps $>.08)^{8}$.

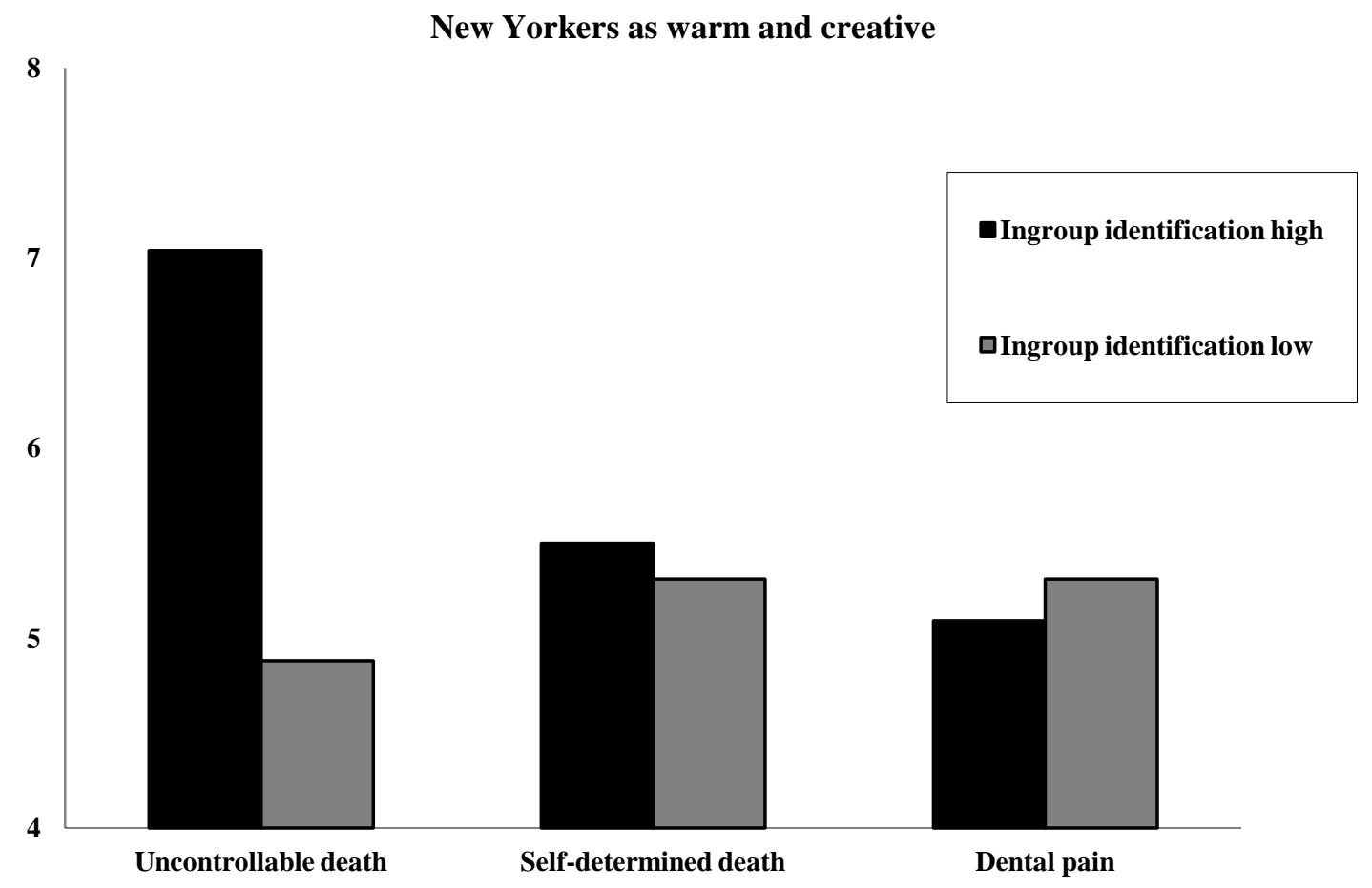

Figure 1. Evaluation of the ingroup (New Yorkers) as warm and creative as a function of ingroup identification and experimental condition.

\footnotetext{
${ }^{7}$ Ingroup identification was not affected by the contrasts ( $\left.p s>.20\right)$.

${ }^{8}$ Exploratory analyses revealed that similar to the pattern observed for the positive evaluation of New Yorkers, a critical contrast $(+2-1-1)$ $\times$ identification interaction occurred for the fifth factor, describing New Yorkers as just and brazen, $b=.15 ; t(38)=2.56 ; p=.02 ; \beta=.39$. However, simple slope analyses indicate only a marginally significant contrast effect for high identifiers, $b=.44 ; t(38)=1.85 ; p=.07 ; \beta$ $=.41$ and, in the opposite direction, for low identifiers, $b=-.35 ; t(38)=-1.67 ; p=.10 ; \beta=-.33$. Ingroup identification did not significantly interact with any of the other factor scores (all $p s>.05$ ).
} 


\subsubsection{Discussion}

Study 1 replicated the effect of uncontrollable vs. self-determined death on ingroup evaluations in the individualistic American culture. New Yorkers tended to more strongly ascribe a positive stereotype (warm and creative) to their ingroup following reminders of uncontrollable death compared to self-determined death or dental pain. Importantly, this effect was only present for those who highly identified with New Yorkers, demonstrating that the effects of lack of control were indeed group-based.

Of interest, uncontrollable vs. self-determined death only elicited bias in the form of positive ingroup evaluations but not negative evaluations of the outgroup. This is in line with research on the positive-negative asymmetry in ingroup bias (Mummendey, Otten, Berger \& Kessler, 2000) and with findings that mortality salience's effects on the evaluation of outgroup members are contingent on outgroup members' behavior (See \& Petty, 2006). This is also in line with the model of group-based control (Fritsche et al., 2013). Restoring a sense of control through the ingroup means that people act as ingroup members (vs. individual persons). Whereas this usually involves a positive perception of the ingroup, perceptions of the outgroup should only be affected by control restoration concerns when outgroup derogation seems normative for the ingroup (e.g., in cases of intergroup conflict) or other ways of improving the positive distinctiveness of the ingroup are not available.

\subsection{Study 2}

Study 2 examined the effect of uncontrollable vs. self-determined death on worldview defense in a Chinese collectivistic culture. Extant research has already shown that reminders of one's own death increased worldview defense among Chinese (e.g., Du et al., 2013). Therefore, Study 2 adopted a different measure on group-based control restoration: evaluations on moral transgression. This measure is common in terror management research (e.g. Rosenblatt et al., 1989; Florian \& Mikulicer, 1997), but has not been used in research on group-based control restoration. If a sense of control is threatened by uncontrollable death, people would allocate harsher punishments to moral transgressors because such a collective action can also help people restore the perception of control over the world. Hence, we hypothesized that uncontrollable death salience would lead people to allocate harsher punishments to moral transgressors than both the control (non-mortality-salient) condition and controllable death (self-determined dying) condition.

\subsubsection{Method}

1) Participants

Participants were 58 undergraduates (35 females) from a university in mainland China aged between 17 and 22 years $(M=18.79, S D=0.87)$. The data of two participants were excluded from the analyses because their scores on the evaluations on moral transgression were more than 2.5 standard deviations from the mean.

2) Procedure

At the beginning of the study, participants completed two questionnaires; one was said to be on self-relevant information and anxiety and the other on social judgment. After completing a Chinese version of the Rosenberg Self-Esteem Scale (Rosenberg, 1965) ${ }^{9}$, participants were randomly assigned to one of the three conditions: uncontrollable death, self-determined death, or watching TV (Fritsche et al., 2008). The manipulations on uncontrollable death and self-determined death were the same as in Study 1. In the control condition, participants answered parallel questions about watching TV, which is also frequently used as a control task in mortality salience research (Burke et al., 2010). After that, participants completed a Chinese version of the 20-item PANAS as a filler task (Watson et al., 1988) ${ }^{10}$ since the effects of severe threat (e.g., mortality salience, uncertainty) have been shown to be most pronounced after a delay (Greenberg, Pyszczynski, Solomon, Simon, \& Breus, 1994).

Next, participants read two legal cases described in the allegedly unrelated second study and a statement which introduced the general boundaries of punishment including imprisonment and fine. Participants were required to indicate their preferred magnitude of punishment in the form of imprisonment and a fine for each case.

In the first case, a male criminal offender had been arrested for raping a girl. The bond statement noted that a criminal for this class of offense would usually be imprisoned for 1 to 10 years, and would be fined between ¥0 to $¥ 6000$. Participants then responded to four questions, rating them on 5-point scales: a) How severe do you find this crime? $(1=$ not severe, 5 = very severe $)$, b) How hard would you punish this criminal? $(1=$ not severe-

\footnotetext{
${ }^{9}$ Self-esteem did not moderate the effect of uncontrollable death and is thus not referred to in the remainder of the present text.

${ }^{10}$ There was no significant difference in positive or negative affect across the mortality salience conditions ( $p s>.14$ ).
} 
ly, 5 = very severely), c) How many years of imprisonment would you allocate to the perpetrator? (1 = 1 - 2 years, $5=9-10$ years), d) How much would you fine the perpetrator? $(1=¥ 0-1200,5=¥ 4801-6000)$.

In the second case, a man drove without a license and slightly injured a traffic police officer. The statement noted that a criminal of this class of offense would usually be imprisoned for 0 to 75 days, and would be fined between $¥ 0$ to $¥ 3000$. The rating questions that followed were identical with those used in the first case except that the rating scales were adapted according to the minimum and maximum in the second case, that is, the time of imprisonment ( $1=0$ - 15 days, $5=61-75$ days $)$ and the amount of fine $(1=¥ 0-600,5=¥ 2401$ - 3000). Finally, participants answered some demographic questions, were thoroughly debriefed and thanked.

\subsubsection{Results}

We computed a composite mean score of worldview defense $(\alpha=.77)$ using the eight ratings for the two cases. Higher scores indicated that participants made more severe moral judgments and allocated more severe punishments.

We tested whether the Chinese sample would show a pattern of results consistent with previous studies (Fritsche et al., 2008). That is, whether cultural worldview defense would be higher in the uncontrollable death than in the self-determined death and control conditions. Regression analysis with the critical and orthogonal contrasts as predictors were conducted for worldview defense. As hypothesized, the critical contrast $(+2-1-1)$ revealed a significant effect, $\beta=.35, \mathrm{SE}=.05, t(53)=2.76, p=.008$, whereas the orthogonal contrast $(01-1)$ effect was not significant, $\beta=.17, \mathrm{SE}=.08, t(53)=1.38, p=.17$. This indicates that participants showed lower worldview defense in both the self-determined death $(M=4.09, S D=.39)$ and the control conditions $(M=3.86$, $S D=.62)$, compared to the uncontrollable death condition $(M=4.36, S D=.42)$.

\subsubsection{Discussion}

Study 2 replicated the uncontrollable vs. self-determined death effect in a Chinese sample. Mortality salience increased negative reactions to moral transgressions, but only when it was described as uncontrollable, not when it was described as self-determined. This result increases support for a control-based explanation of the effects of mortality salience on cultural worldview defense since classic mortality salience effects were eliminated when control over one's own death was made salient. This is the first study to show the differential effect of self-determined versus uncontrollable death in a collectivistic culture.

\section{General Discussion}

The mortality of the self is perhaps the ultimate reminder that we have only limited control in our life and death. As such, death reminders can threaten a person's sense of general control (Martin, 1999) and elicit control restoration efforts (such as defending ingroups and associated cultural worldviews). The present studies found that mortality salience increased the defense of cultural ingroups and their worldviews when death was framed as uncontrollable rather than self-determined. Study 1 showed the effect of uncontrollable death on ethnocentric responses was only present in people who highly identified with their ingroup. This further supports a groupbased control explanation in which control is restored by groups that represent the self.

The studies are also the first to show the uncontrollable death effect in non-German samples (i.e., China and the United States) that not only differ from the German culture but also from each other. Study 1 replicated the effects in the United States, a culture that is assumed to be markedly more individualistic than Germany (Hofstede, 2015). Study 2 showed that people from a collectivist culture were also more reactive after personal control was threatened compared to those who did not experience a lack of control. While further studies are needed, these findings provide promising preliminary evidence for the cross-cultural validity of the effects of uncontrollable death salience on worldview defense.

In recent years, effects of control threat on human social behavior have gathered some attention. Aaron Kay and colleagues (Kay, Gaucher, McGregor, \& Nash, 2010; Kay, Gaucher, Napier, Callan, \& Laurin, 2008; Kay, Whitson, Gaucher, \& Galinsky, 2009; Landau, Kay, \& Whitson, 2015; Laurin, Kay, \& Moscovitch, 2008) proposed that threats to personal control can elicit "feelings of randomness and chaos in the social world" (Kay et al., 2008: p. 18). This can lead people to support external systems of control, such as God or the government in an attempt to re-establish a sense that the world is controlled by powerful agents. Complementing the explanation of control effects, Fritsche and his colleagues (Fritsche et al., 2011, 2013; Stollberg et al., 2015) propose a me- 
chanism of group-based control restoration in which threats to personal control are thought to lead people to restore control through the self. This is why people support institutions or groups that are incorporated into their sense of self (e.g., through self-categorization; Turner, Hogg, Oakes, Reicher, \& Wetherell, 1987) and act in terms of the social instead of the personal self. That is, when personal control is threatened, people are assumed to defend primarily their own God and their own government. Study 1 provides evidence that cultural worldview defense shown in response to control threat may indeed be a group-based process. Here, only those New York citizens who were highly identified with their city responded to control threat through increased positive ratings of New Yorkers. Other studies also point to the decisive role of group membership in ethnocentric reactions to conventional death reminders. For example, Giannakakis and Fritsche (2011) showed that following death reminders English students exhibited increased ingroup bias in resource allocations between English and Scottish students, but only when English self-categorization was made salient. When self-categorization as a student was salient, death salience had no effect on ingroup bias. This illustrates that people do not necessarily defend any system that may control the world, but prefer those that are seen as representing the self.

Although thinking and acting as a group member seems to provide a general means to fight threat to control, work by Shepherd, Kay, Landau, and Keefer (2011) suggests that collective threat responses may differ in emphasis across different specific control threats. Undergraduates who were made to think of specific uncontrollable events that have happened to them in the recent months more strongly supported an ingroup leader when he promised to restore order and control (by reducing economic stress) than when he promised symbolic immortality (through future thriving of the ingroup). People who were reminded of their own death supported both leaders to the same degree. Thus, despite the general value of collective thinking and action for control restoration processes across different domains of control loss (Fritsche et al., 2008, 2013; Fritsche, Koranyi, Beyer, Jonas, \& Fleischmann, 2009; Greenaway et al., 2014; Stollberg et al., 2015, submitted), specific features of the ingroup (e.g., prosperity) may be of particular value when they address the actual source of control threat (e.g., economic threats).

One may wonder how the evaluation of a moral transgressor (Study 2) relates to processes of group-based control over and above the fact that it occurs after manipulations of control threat. We argue that harsh punishments allocated to moral transgressors are a form of collective action in terms of the "we" (see Kreindler, 2005; Kessler \& Cohrs, 2008). This is because moral transgressions endanger the validity of shared ingroup norms and thus the ingroup's moral integrity and ingroup cooperation.

The current research has two limitations. Samples from the United States and China were utilized to represent highly individualistic and highly collectivistic cultures, respectively. Although this approach has been commonly adopted in cross-cultural research, it is plausible that the US participants were not very independent and the Chinese participants were not very interdependent. Future replication research should directly measure participants' independent and interdependent self-construal and examine its association with group-based control restoration. In addition, we followed the experimental paradigm developed by Fritsche et al. (2008) and compared uncontrollable death with self-determined death. Future replication research may benefit from manipulating or measuring personal control in a context other than death to test its effects on cultural worldview defense.

\section{Conclusion}

Overall, the present studies provide additional support to the idea that a lack of control leads people to defend their ingroups and their cultural worldviews (Fritsche et al., 2008). We would argue that the lack of control associated with death is the primary driver of the cultural worldview defense reaction observed after mortality salience (although unique effects of existential threat may exist with regard to other dependent variables, such as striving for offspring; Fritsche et al., 2007; Wisman \& Goldenberg, 2005). Evidence for this can be seen in our findings that participants who feel less control over their death showed more worldview defense. Importantly, the effects of lack of control on worldview defense are still present even when the lack of control is not associated with death (Agroskin \& Jonas, 2013; Fritsche et al., 2008). We propose that clinging to and defending one's ingroup restores a sense of control when people's global sense of control is threatened.

\section{Conflict of Interest Statement}

The Authors declare that there is no conflict of interest. 


\section{Funding}

Dr. Talati was supported by a UWA Completion Scholarship. Study 1 was supported by the German Research Association (grant FR 2067/1-1).

\section{References}

Agroskin, D., \& Jonas, E. (2013). Controlling Death by Defending Ingroups: Mediational Insights into Terror Management and Control Restoration. Journal of Experimental Social Psychology, 49, 1144-1158. http://dx.doi.org/10.1016/j.jesp.2013.05.014

Aiken, L. S., \& West, S. G. (1991). Multiple Regression: Testing and Interpreting Interactions. Thousand Oaks: CA Sage Publications.

Arndt, J., \& Greenberg, J. (1999). The Effects of a Self-Esteem Boost and Mortality Salience on Responses to Boost Relevant and Irrelevant Worldview Threats. Personality and Social Psychology Bulletin, 25, 1331-1341. http://dx.doi.org/10.1177/0146167299259001

Burke, B. L., Martens, A., \& Faucher, E. H. (2010). Two Decades of Terror Management Theory: A Meta-Analysis of Mortality Salience Research. Personality and Social Psychology Review, 14, 155-195. http://dx.doi.org/10.1177/1088868309352321

Castano, E., \& Dechesne, M. (2005). On Defeating Death: Group Reification and Social Identification as Immortality Strategies. In W. Stroebe, \& M. Hewstone (Eds.), European Review of Social Psychology (Vol. 16, pp. 221-255). Hove: Psychology Press. http://dx.doi.org/10.1080/10463280500436024

Castano, E., Yzerbyt, V., Paladino, M.-P., \& Sacchi, S. (2002). I Belong, Therefore, I Exist: Ingroup Identification, Ingroup Entitativity, and Ingroup Bias. Personality and Social Psychology Bulletin, 28, 135-143. http://dx.doi.org/10.1177/0146167202282001

Cheng, C., Cheung, S., Chio, J. H., \& Chan, M. S. (2013). Cultural Meaning of Perceived Control: A Meta-Analysis of Locus of Control and Psychological Symptoms across 18 Cultural Regions. Psychological Bulletin, 139, 152-188. http://dx.doi.org/10.1037/a0028596

Du, H., Jonas, E., Klackl, J., Agroskin, D., Hui, E. K. P., \& Ma, L. (2013). Cultural Influences on Terror Management: Independent and Interdependent Self-Esteem as Anxiety Buffers. Journal of Experimental Social Psychology, 49, 10021011. http://dx.doi.org/10.1016/i.jesp.2013.06.007

Florian, V., \& Mikulincer, M. (1997). Fear of Death and the Judgment of Social Transgressions: A Multidimensional Test of Terror Management Theory. Journal of Personality and Social Psychology, 73, 369-380. http://dx.doi.org/10.1037/0022-3514.73.2.369

Fritsche, I., Jonas, E., \& Fankhänel, T. (2008). The Role of Control Motivation in Mortality Salience Effects on Ingroup Support and Defense. Journal of Personality and Social Psychology, 95, 524-541. http://dx.doi.org/10.1037/a0012666

Fritsche, I., Jonas, E., \& Kessler, T. (2011). Collective Reactions to Threat: Implications for Intergroup Conflict and Solving Societal Crises. Social Issues and Policy Review, 5, 101-136. http://dx.doi.org/10.1111/j.1751-2409.2011.01027.X

Fritsche, I., Jonas, E., Ablasser, C., Beyer, M., Kuban, J., Manger, A.-M., \& Schultz, M. (2013). The Power of We: Evidence for Group-Based Control Restoration. Journal of Experimental Social Psychology, 49, 19-32.

http://dx.doi.org/10.1016/j.jesp.2012.07.014

Fritsche, I., Jonas, E., Fischer, P., Koranyi, N., Berger, N., \& Fleischmann, B. (2007). Mortality Salience and the Desire for Offspring. Journal of Experimental Social Psychology, 43, 753-762. http://dx.doi.org/10.1016/j.jesp.2006.10.003

Fritsche, I., Jonas, E., Klackl, J., \& Decker, O. (2013). Group-Based Control under Conditions of Unemployment Threat. Unpublished Manuscript, Leipzig: University of Leipzig.

Fritsche, I., Koranyi, N., Beyer, C., Jonas, E., \& Fleischmann, B. (2009). Enemies Welcome: Personal Threat and Reactions to Outgroup Doves and Hawks. International Review of Social Psychology, 22, 157-179.

Giannakakis, A. E., \& Fritsche, I. (2011). Social Identities, Group Norms, and Threat: On the Malleability of Ingroup Bias. Personality and Social Psychology Bulletin, 37, 82-93.

Greenaway, K. H., Louis, W. R., Hornsey, M. J., \& Jones, J. M. (2014). Perceived Control Qualifies the Effects of Threat on Prejudice. British Journal of Social Psychology, 53, 422-442. http://dx.doi.org/10.1111/bjso.12049

Greenberg, J., Pyszczynski, T., Solomon, S., Rosenblatt, A., Veeder, M., Kirkland, S., \& Lyon, D. (1990). Evidence for Terror Management Theory II: The Effects of Mortality Salience on Reactions to Those Who Threaten or Bolster the Cultural Worldview. Journal of Personality and Social Psychology, 58, 308-318. http://dx.doi.org/10.1037/0022-3514.58.2.308

Greenberg, J., Pyszczynski, T., Solomon, S., Simon, L., \& Breus, M. (1994). Role of Consciousness and Accessibility of Death-Related Thoughts in Mortality Salience Effects. Journal of Personality and Social Psychology, 67, 627-637. 
http://dx.doi.org/10.1037/0022-3514.67.4.627

Greenberg, J., Simon, L., Pyszczynski, T., Solomon, S., \& Chatel, D. (1992a). Terror Management and Tolerance: Does Mortality Salience Always Intensify Negative Reactions to Others Who Threaten One's Worldview? Journal of Personality and Social Psychology, 63, 212-220. http://dx.doi.org/10.1037/0022-3514.63.2.212

Greenberg, J., Solomon, S., \& Pyszczynski, T. (1997). Terror Management Theory of Self-Esteem and Cultural Worldviews: Empirical Assessments and Conceptual Refinements. In M. P. Zanna (Ed.), Advances in Experimental Social Psychology (Vol. 29, pp. 61-139). New York: Academic Press.

Henrich, J., Heine, S. J., \& Norenzayan, A. (2010). Most People are Not Weird. Nature, 466, 29. http://dx.doi.org/10.1038/466029a

Hofstede, G. (1991). Cultures and Organizations: Software of the Mind. London: McGraw-Hill.

Hofstede, G. (2015). The Hofstede Centre: Strategy, Culture, Change. http://geert-hofstede.com/countries.html

Iyengar, S. S., \& Lepper, M. R. (1999). Rethinking the Value of Choice: A Cultural Perspective on Intrinsic Motivation. Journal of Personality and Social Psychology, 76, 349-366. http://dx.doi.org/10.1037/0022-3514.76.3.349

Jarvis, B. G. (2004a). MediaLab (Version 2004) [Computer Software]. New York: Empirisoft Corporation.

Jarvis, B. G. (2004b). DirectRT (Version 2004) [Computer Software]. New York: Empirisoft Corporation.

Kay, A. C., Gaucher, D., McGregor, I., \& Nash, K. (2010). Religious Belief as Compensatory Control. Personality and Social Psychology Review, 14, 37-48. http://dx.doi.org/10.1177/1088868309353750

Kay, A. C., Gaucher, D., Napier, J. L., Callan, M. J., \& Laurin, K. (2008). God and the Government: Testing a Compensatory Control Mechanism for the Support of External Systems. Journal of Personality and Social Psychology, 95, 18-35. http://dx.doi.org/10.1037/0022-3514.95.1.18

Kay, A. C., Whitson, J. A., Gaucher, D., \& Galinsky, A. D. (2009). Compensatory Control: Achieving Order through the Mind, Our Institutions, and the Heavens. Current Directions in Psychological Science, 18, 264-268. http://dx.doi.org/10.1111/j.1467-8721.2009.01649.x

Kazén, M., Baumann, N., \& Kuhl, J. (2005). Self-Regulation after Mortality Salience: National Pride Feelings of Action-Oriented German Participants. European Psychologist, 10, 218-228 http://dx.doi.org/10.1027/1016-9040.10.3.218

Kessler, T., \& Cohrs, J. C. (2008). The Evolution of Authoritarian Processes: Fostering Cooperation in Large-Scale Groups. Group Dynamics: Theory, Research, and Practice, 12, 73-84. http://dx.doi.org/10.1037/1089-2699.12.1.73

Kreindler, S. A. (2005). A Dual Group Processes Model of Individual Differences in Prejudice. Personality and Social Psychology Review, 9, 90-107. http://dx.doi.org/10.1207/s15327957pspr0902_1

Landau, M. J., Kay, A. C., \& Whitson, J. A. (2015). Compensatory Control and the Appeal of a Structured World. Psychological Bulletin, 141, 694-722. http://dx.doi.org/10.1037/a0038703

Laurin, K., Kay, A. C., \& Moscovitch, D. A. (2008). On the Belief in God: Towards an Understanding of the Emotional Substrates of Compensatory Control. Journal of Experimental Social Psychology, 44, 1559-1562. http://dx.doi.org/10.1016/j.jesp.2008.07.007

Markus, H. R., Uchida, Y., Omoregie, H., Townsend, S. S. M., \& Kitayama, S. (2006). Going for the Gold: Models of Agency in Japanese and American Contexts. Psychological Science, 17, 103-112. http://dx.doi.org/10.1111/j.1467-9280.2006.01672.x

Martin, L. L. (1999). I-D Compensation Theory: Some Implications of Trying to Satisfy Immediate-Return Needs in a Delayed-Return Culture. Psychological Inquiry, 10, 195-208. http://dx.doi.org/10.1207/S15327965PLI1003_1

Mirowsky, J., \& Ross, C. E. (1991). Eliminating Defense and Agreement Bias from Measures of the Sense of Control: A 2 X 2 Index. Social Psychology Quarterly, 54, 127-145. http://dx.doi.org/10.2307/2786931

Morling, B., \& Kitayama, S. (2007). Culture and Motivation. In J. Shah, \& W. Gardner (Eds.), Handbook of Motivation Science (pp. 417-432). New York: Guilford.

Mummendey, A., Otten, S., Berger, U., \& Kessler, T. (2000). Positive-Negative Asymmetry in Social Discrimination: Valence of Evaluation and Salience of Categorization. Personality and Social Psychology Bulletin, 26, 1258-1270. http://dx.doi.org/10.1177/0146167200262007

Open Science Collaboration (2015). Estimating the Reproducibility of Psychological Science. Science, 349, aac4716. http://dx.doi.org/10.1126/science.aac4716

Rosenberg, M. (1965). Society and the Adolescent Self-Image. Princeton, NJ: Princeton University Press.

Sastry, J., \& Ross, C. E. (1998). Asian Ethnicity and the Sense of Personal Control. Social Psychology Quarterly, 6, 101120. http://dx.doi.org/10.2307/2787064

See, Y. H. M., \& Petty, R. E. (2006). Effects of Mortality Salience on Evaluation of Ingroup and Outgroup Sources: The Impact of Pro-Versus Counterattitudinal Positions. Personality and Social Psychology Bulletin, 32, 405-416. 
http://dx.doi.org/10.1177/0146167205282737

Shepherd, S., Kay, A. C., Landau, M. J., \& Keefer, L. A. (2011). Evidence for the Specificity of Control Motivations in Worldview Defense: Distinguishing Compensatory Control from Uncertainty Management and Terror Management Processes. Journal of Experimental Social Psychology, 47, 949-958. http://dx.doi.org/10.1016/j.jesp.2011.03.026

Smith, P. B., Trompenaars, F., \& Dugan, S. (1995). The Rotter Locus of Control Scale in 43 Countries: A Test of Cultural Relativity. International Journal of Psychology, 30, 377-400. http://dx.doi.org/10.1080/00207599508246576

Stollberg, J., Fritsche, I., \& Bäcker, A. (2015a). Striving for Group Agency: Threat to Personal Control Increases the Attractiveness of Agentic Groups. Frontiers in Psychology, 6, 649. http://dx.doi.org/10.3389/fpsyg.2015.00649

Stollberg, J., Fritsche, I., \& Jonas, E. (2015b). Threat to Personal Control Strengthens the Expression of the Social Self: Conformity to Ingroup Change Norms as a Group-Based Response. Manuscript Submitted for Publication, Leipzig: University of Leipzig.

Turner, J. C., Hogg, M. A., Oakes, P. J., Reicher, S. D., \& Wetherell, M. S. (1987). Rediscovering the Social Group: A Self-Categorization Theory. Oxford, England: Blackwell.

Watson, D., Clark, L. A., \& Tellegen, A. (1988). Development and Validation of brief Measures of Positive and Negative Affect: The PANAS Scales. Journal of Personality and Social Psychology, 54, 1063-1070. http://dx.doi.org/10.1037/0022-3514.54.6.1063

Wisman, A., \& Goldenberg, J. L. (2005). From the Grave to the Cradle: Evidence That Mortality Salience Engenders a Desire for Offspring. Journal of Personality and Social Psychology, 89, 46-61. http://dx.doi.org/10.1037/0022-3514.89.1.46

\section{Submit or recommend next manuscript to SCIRP and we will provide best service for you:}

Accepting pre-submission inquiries through Email, Facebook, Linkedin, Twitter, etc A wide selection of journals (inclusive of 9 subjects, more than 200 journals)

Providing a 24-hour high-quality service

User-friendly online submission system

Fair and swift peer-review system

Efficient typesetting and proofreading procedure

Display of the result of downloads and visits, as well as the number of cited articles

Maximum dissemination of your research work

Submit your manuscript at: http://papersubmission.scirp.org/ 